\title{
Adjustable pretilt angle of nematic 4-n-pentyl-4' -cyanobiphenyl on self-assembled monolayers formed from organosilanes on square-wave grating silica surfaces
}

\author{
Da-Ren Chiou, Kuan-Yu Yeh, and Li-Jen Chen ${ }^{\text {a) }}$ \\ Department of Chemical Engineering, National Taiwan University, Taipei 10617, Taiwan, Republic of China
}

(Received 11 October 2005; accepted 7 March 2006; published online 31 March 2006)

\begin{abstract}
The square-wave grating silica surfaces are fabricated by soft embossing silica sol-gel precursor on glass substrates with an elastomeric polydimethylsiloxane mold. The patterned silica surface could induce the planar alignment of liquid crystal 4- $n$-pentyl-4' -cyanobiphenyl (5CB) along the direction of microgrooves but with no pretilt angle. The pretilt angle of $5 \mathrm{CBs}$ is adjusted from $0^{\circ}$ to $90^{\circ}$ by the further deposition of organosilane self-assembled monolayers with different functional end-groups on the patterned silica surfaces. (C) 2006 American Institute of Physics.
\end{abstract}

[DOI: $10.1063 / 1.2191472$ ]

In the liquid crystal display industry, the unidirectional mechanical rubbing process on polymer-coated substrates with a velvet cloth is almost exclusively applied to align liquid crystals. The rubbing process induces grooves in the polymer surfaces and also realigns polymer backbone that enables liquid crystal molecules to align along the direction of the grooves. The liquid crystal alignment depends both on the surface topography and on the chemical nature of the surface (such as the realignment of polymer backbone). Recent studies $^{1-3}$ pointed out that the realignment of polymer chains during the mechanical rubbing process is particularly responsible for the liquid crystal alignment rather than the groove effect. In particular, the modern nonrubbing photoinduced liquid crystal alignment by polarized light exposure, ${ }^{4}$ which does not involve the production of microgrooves, also confirms that the realignment of the polymer main chains dominates the liquid crystal alignment. It remains a controversial problem that whether the surface topography ${ }^{5,6}$ or the chemical nature of the surface ${ }^{1-3}$ dominates the planar alignment of nematic liquid crystals. Therefore, we applied the soft embossing method to fabricate square-wave grating silica films, which do not involve any polymer main chain, to solely investigate the surface topography effect on the liquid crystal alignment in this study. On the other hand, the chemical nature of the surface was manipulated by growing the self-assembled monolayers (SAMs) formed from organosilanes on the square-wave grating silica surfaces. The pretilt angle of nematic liquid crystal 4- $n$-pentyl-4'-cyanobiphenyl (5CB) increases along with an increase in the hydrophobicity of the SAM surfaces.

The microgrooved silica surface is fabricated by soft embossing method, ${ }^{7}$ which simply applies an elastomeric polydimethylsiloxane (PDMS) mold as often used in soft lithography ${ }^{8}$ to an imprinting process. Figure 1 schematically illustrates the soft embossing process. The PDMS (SylgardTM184, Dow Corning Co.) mold is fabricated by casting prepolymer against a silicon master of square-wave grating pattern prepared either by photolithography or by the electron-beam method. We first spread a drop of silica sol-gel precursor prepared according to the well-known procedure ${ }^{9}$ onto the clean glass substrate. Then the patterned

\footnotetext{
${ }^{\text {a) }}$ Author to whom correspondence should be addressed; electronic mail:
} ljchen@ntu.edu.tw
PDMS mold is embossed on this substrate and followed by baking at $50{ }^{\circ} \mathrm{C}$ for $1 \mathrm{~h}$. After peeling off the PDMS mold, the patterned silica surface with periodical grooves is fabricated. The slow heat treatment of these patterned silica surfaces is then applied up to $400{ }^{\circ} \mathrm{C}$ and the patterned structure shrinks obviously in the direction perpendicular to the substrate surface. ${ }^{7}$ However, there is no cracking of the patterned structures after the slow heat treatment stage. This is consistent with the observation of Chou et al. ${ }^{10}$

The crossed polarized optical microscopy (Zeiss) is used to observe alignment of the nematic liquid crystal $5 \mathrm{CB}$ on these patterned silica surfaces. The liquid crystal cell is composed of two patterned silica substrates with parallel groove direction and these two substrates are kept apart by inserting $10 \mu \mathrm{m}$ Mylar films (DuPont Films) at the two longer edges. The filling of the $5 \mathrm{CBs}$ is driven by capillarity. Figure 2 shows the optical micrographs. The alignment of 5CBs on the patterned silica surface with $391 \mathrm{~nm}$ groove width and $350 \mathrm{~nm}$ groove depth is uniformly planar along the groove direction, as shown in Fig. 2(a) and 2( $\left.\mathrm{a}^{\prime}\right)$. The surface topology is determined by the atomic force microscope (Nano-

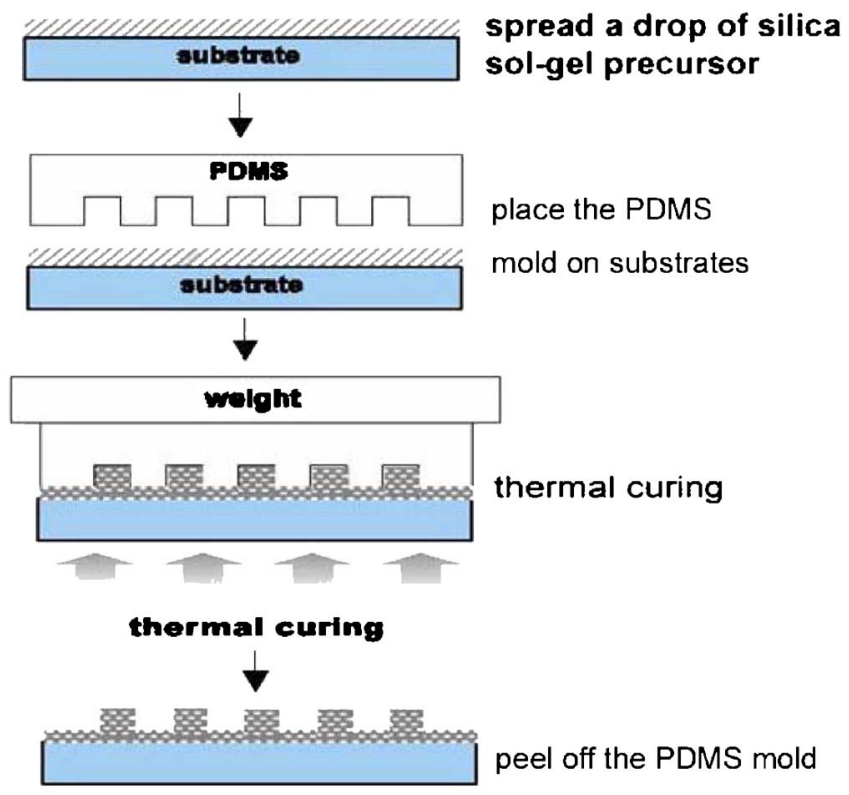

FIG. 1. (Color online) The schematic representation of the fabrication of patterned silica surfaces by soft embossing method. 

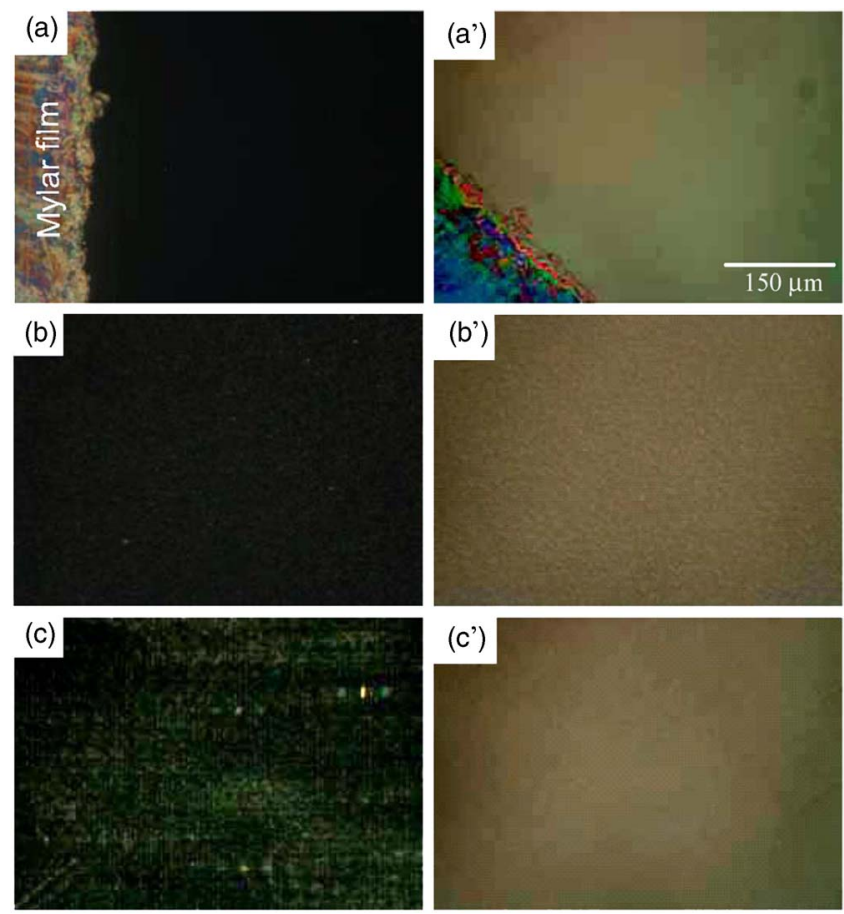

FIG. 2. (Color online) The optical micrographs of liquid crystal alignment on the patterned silica surfaces taken between crossed polarizers. [(a) and $\left.\left(a^{\prime}\right)\right] 391 \mathrm{~nm}$ groove width, [(b) and $\left.\left(\mathrm{b}^{\prime}\right)\right] 1.98 \mu \mathrm{m}$ groove width, and [(c) and $\left.\left(\mathrm{c}^{\prime}\right)\right] 5.31 \mu \mathrm{m}$ groove width. All the micrographs on the left hand side, (a), (b), and (c), are taken with the groove direction parallel to one of the polarizer axes, and all the micrographs on the right hand side, $\left(\mathrm{a}^{\prime}\right),\left(\mathrm{b}^{\prime}\right)$, and $\left(\mathrm{c}^{\prime}\right)$, are taken with the groove direction at $45^{\circ}$ to each polarizer axis.

scope IIIa, Digital Instrument, Santa Barbara). It is interesting to note that when the groove width and the groove depth are increased to $1.98 \mu \mathrm{m}$ and $918 \mathrm{~nm}$, respectively, the liquid crystal alignment remains planar, as shown in Figs. 2(b) and $2\left(b^{\prime}\right)$. However, when the groove width is increased to $5.31 \mu \mathrm{m}$ whereas the groove depth remains $350 \mathrm{~nm}$, there are microdomains, as shown in Figs. 2(c) and 2( $\left.\mathrm{c}^{\prime}\right)$, indicating that the liquid crystal alignment is not uniformly planar along the groove direction anymore.

Previous studies ${ }^{5,6}$ show that the physical topography of a surface has an effect on the orientation of liquid crystal alignment. Berreman ${ }^{5}$ rubbed the glass substrates with diamond powder to produce microgrooves on the surfaces. He claimed that the groove effect is the primary factor that induces the alignment of liquid crystal molecules toward the rubbing direction according to the minimization of the elastic energies in a nematic liquid crystal. According to the expression of the anchoring energy of Berreman, ${ }^{5}$ the anchoring energy is strongly dependent on the groove geometry. That is, the greater the groove depth, the higher the anchoring energy would be. It is plausible to conjecture that a substrate with a sufficient deep groove depth could induce uniform alignment of liquid crystal molecules that are confined even in a large groove width. Our experiment results support this conjecture. Figure 3 shows the optical micrographs for the alignment of $5 \mathrm{CBs}$ between two patterned silica surfaces with $2.83 \mu \mathrm{m}$ groove width and different groove depths. One can see in Figs. 3(a), 3( $\left.a^{\prime}\right), 3(b)$, and $3\left(b^{\prime}\right)$, that the alignment of $5 \mathrm{CBs}$ is not uniform for $55 \mathrm{~nm}$ groove depth but becomes more uniform for $600 \mathrm{~nm}$ groove depth. Eventually, Figs. 3(c) and 3( $\left.\mathrm{c}^{\prime}\right)$ show uniformly planar alignment when the groove depth is further increased to $1200 \mathrm{~nm}$. DTS- and OTS-SAMs, which is a low energy and very hy-
Downloaded 12 Nov 2008 to 140.112 .113 .225 . Redistribution subject to AIP license or copyright; see http://apl.aip.org/apl/copyright.jsp
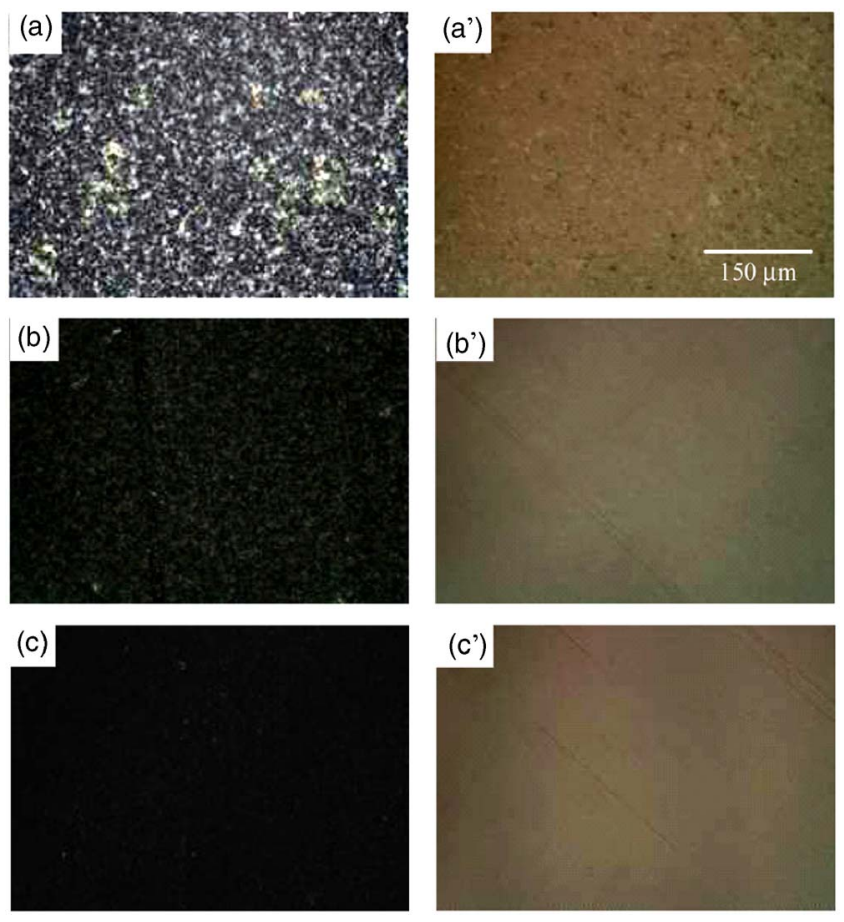

FIG. 3. (Color online) Optical micrographs of liquid crystal alignment taken between crossed polarizers for the patterned silica surfaces with $2.83 \mu \mathrm{m}$ groove width at three different groove depths: $55 \mathrm{~nm}\left[(\mathrm{a})\right.$ and $\left.\left(\mathrm{a}^{\prime}\right)\right], 600 \mathrm{~nm}$ $\left[(\mathrm{b})\right.$ and $\left.\left(\mathrm{b}^{\prime}\right)\right]$, and $1200 \mathrm{~nm}\left[(\mathrm{c})\right.$ and $\left.\left(\mathrm{c}^{\prime}\right)\right]$. All the micrographs on the left hand side, (a), (b), and (c), are taken with the groove direction parallel to one of the polarizer axes, and all the micrographs on the right hand side, $\left(\mathrm{a}^{\prime}\right),\left(\mathrm{b}^{\prime}\right)$, and $\left(\mathrm{c}^{\prime}\right)$, are taken with the groove direction at $45^{\circ}$ to each polarizer axis.

The anchoring energy is further determined to explore the quality of anchoring of $5 \mathrm{CBs}$ on the patterned silica surfaces fabricated by the soft embossing process. The cell is assembled with a cell gap of $10 \mu \mathrm{m}$. The groove direction of surfaces is perpendicular to each other: one patterned silica substrate and a conventionally rubbed polyimide counter plate. The cell rotation method ${ }^{11}$ is applied to determine the surface anchoring energies by detecting the twist angle of liquid crystal molecules in the liquid crystal cell. The patterned silica surfaces with $1055 \mathrm{~nm}$ groove width and $917 \mathrm{~nm}$ groove depth exhibit higher anchoring energies $\left(7.1 \times 10^{-5} \mathrm{~J} / \mathrm{m}^{2}\right)$ than those of the conventional rubbed polyimide surfaces $\left(1.7 \times 10^{-5} \mathrm{~J} / \mathrm{m}^{2}\right.$ in this work). It is believed that the high anchoring energy is mainly due to the large groove depth. Note that the groove width and depth of rubbed polyimide surface are 30 and $4 \mathrm{~nm}$, respectively, in this work.

The square-wave grating silica surfaces have a great potential to serve as liquid crystal alignment layers. However, there is no pretilt angle for 5CBs on the bare silica surfaces of square-wave grating. It is well understood that a broad range of the chemical nature of the silica surface could be modified by the SAMs formed from organosilanes with the hydroxyl groups on the silica surface. In this study, the pretilt angle was measured by the crystal-rotation method ${ }^{12}$ (Autronic-Melchers, TBA 105). When the dodecyltriethoxysilane (DTS, Gelest) or octadecyltrichlorosilane (OTS, Aldrich) SAM is formed on the square-wave grating silica surfaces, the pretilt angle of $5 \mathrm{CBs}$ becomes $90^{\circ}$. That is, the liquid crystal 5CB exhibits homeotropic alignment on the DTS- and OTS-SAMs, which is a low energy and very hyAlP license or copyright; see http://apl.aip.org/apl/copyright.jsp 
drophobic surface. Note that the dimension of the squarewave grating surface used for SAM formation is of $780 \mathrm{~nm}$ spatial period, $390 \mathrm{~nm}$ groove width, and $150 \mathrm{~nm}$ groove depth. On the other hand, the pretilt angle of $5 \mathrm{CBs}$ on the SAM formed from 11-aminoundecyltriethoxysilane (AUTS, Gelest) on the square-wave grating silica surface switches to $1.5^{\circ}$. Note that the AUTS-SAM is a relatively high energy and hydrophilic surface that makes the $5 \mathrm{CB}$ planar anchoring along the groove direction with a small pretilt angle. Here the advancing contact angle of water is used as an index of the hydrophobicity of the surface. The larger is the advancing contact angle of water, more hydrophobic is the surface. The advancing contact angles of the DTS-, OTS-, and AUTS-SAMs on flat surfaces are $110^{\circ}, 110^{\circ}$, and $75^{\circ}$, respectively. The corresponding pretilt angles on the DTS-, OTS-, and AUTS-SAMs are $90^{\circ}, 90^{\circ}$, and $1.5^{\circ}$, respectively. It is plausible to conjecture that the pretilt angle of the liquid crystal $5 \mathrm{CB}$ can be manipulated by tuning the hydrophobicity (chemical nature) of the surface. Therefore, the mixed SAMs of DTS and AUTS on the patterned silica surfaces are prepared from mixtures of DTS and AUTS solutions at molar ratios (DTS/AUTS) of 5 and 10. The advancing contact angles of water on the mixed SAMs at molar ratios of 5 and 10 are $87^{\circ}$ and $92^{\circ}$, respectively. The hydrophobicity increases along with the molar ratio, as expected. Indeed, the pretilt angle of $5 \mathrm{CBs}$ is $3.4^{\circ}$ on the patterned silica surfaces deposited at a molar ratio of 5 and $18.6^{\circ}$ at the molar ratio of 10. It is obvious that the pretilt angle increases along with the advancing contact angle of water and the hydrophobicity of the surface. This observation indicates that it is possible to adjust the pretilt angle of the liquid crystals on the SAM formed from organosilanes with different surface chemical functionalities.

From the above experimental results, the liquid crystal alignment is subject to both the surface topography and the chemical nature of the surface. It is found that the shorter the wavelength of the grating is and the deeper the groove is, the better the planar alignment of nematic liquid crystal becomes. However, the chemical nature of the surface can overwhelm the topographical effect, i.e., the pretilt angle of the liquid crystal 5CB is adjustable by changing the hydrophobicity of the surface of the square-wave grating, as mentioned above. It seems that the chemical nature of the surface is the main factor determining the liquid crystal alignment. In contrast, we would like to demonstrate that the topographical effect can also overwhelm the chemical nature of the surface when the chemical anchoring is weak. The OTSSAMs are prepared on the square-wave grating silica surfaces of $5.7 \mu \mathrm{m}$ spatial period, $2.85 \mu \mathrm{m}$ groove width, and four different groove depths. It is found that the 5CB exhibits homeotropic alignment on these surfaces when the groove depth is 70 or $465 \mathrm{~nm}$, as shown in Fig. 4(a). When the groove depth is further increased, there is a transition of the alignment of $5 \mathrm{CBs}$ from homeotropic to planar, as showed in Figs. 4(b) and 4(c). This observation indicates that when the surface topography is weak, the surface chemical interactions dominate the alignment of 5CBs. While the surface topography gets more pronounced, it becomes the primary factor for the alignment of $5 \mathrm{CBs}{ }^{13}$ Therefore, the liquid crystal alignment is simply the outcome of the competition of the surface topography and the chemical nature of the surface.

In summary, the square-wave grating silica surfaces are fabricated by soft embossing method. The SAMs are pre-
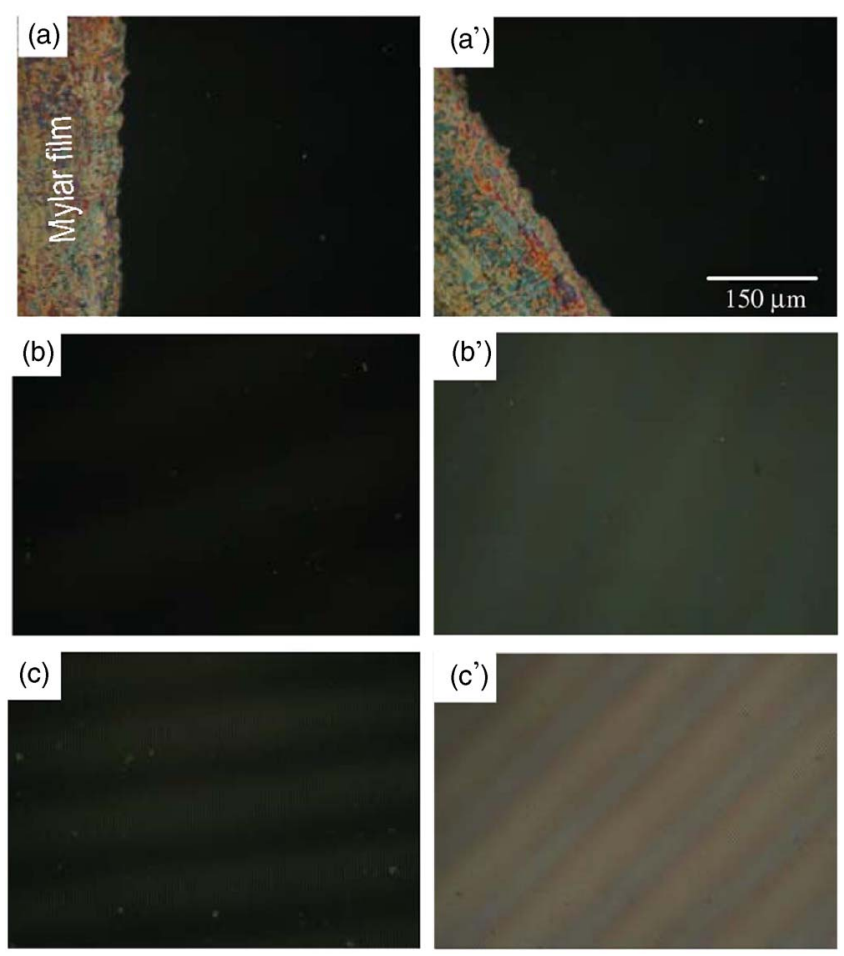

FIG. 4. (Color online) Optical micrographs of liquid crystal alignment taken between crossed polarizers for the patterned silica surfaces deposited with octadecyltrichlorosilane for $2.83 \mu \mathrm{m}$ groove width at three different groove depths: $465 \mathrm{~nm}\left[(\mathrm{a})\right.$ and $\left.\left(\mathrm{a}^{\prime}\right)\right], 1068 \mathrm{~nm}\left[(\mathrm{~b})\right.$ and $\left.\left(\mathrm{b}^{\prime}\right)\right]$, and $1785 \mathrm{~nm}[(\mathrm{c})$ and $\left.\left(c^{\prime}\right)\right]$. All the micrographs on the left hand side, (a), (b), and (c), are taken with the groove direction parallel to one of the polarizer axes, and all the micrographs on the right hand side, $\left(a^{\prime}\right),\left(b^{\prime}\right)$, and $\left(c^{\prime}\right)$, are taken with the groove direction at $45^{\circ}$ to each polarizer axis.

pared on the square-wave grating silica surfaces to manipulate the hydrophobicity of the surface. The pretilt angle of the liquid crystal $5 \mathrm{CB}$ is adjustable by changing the hydrophobicity of the surface of the square-wave grating. It is found that both the surface topography and the chemical nature of the surface are responsible for the liquid crystal alignment and the uniformity of the liquid crystal alignment is strongly dependent on the groove geometry.

${ }^{1}$ J. Stöhr, M. G. Samant, J. Lüning, A. C. Callegari, P. Chaudhari, J. P. Doyle, J. A. Lacey, S. A. Lien, S. Purushothaman, and J. L. Speidell, Science 292, 2299 (2001).

${ }^{2}$ J. M. Geary, J. W. Goodby, A. R. Kmetz, and J. S. Patel, J. Appl. Phys. 62, 4100 (1987).

${ }^{3}$ J. A. Castellano, Mol. Cryst. Liq. Cryst. 94, 33 (1983); A. J. Pidduck, G. P. Bryan-Brown, S. Haslam, R. Bannister, I. Kitely, T. J. McMaster, and L. Boogaard, J. Vac. Sci. Technol. A 14, 1723 (1996).

${ }^{4}$ W. M. Gibbons, P. J. Shannon, S. T. Sun, and B. J. Swetlin, Nature (London) 351, 49 (1991).

${ }^{5}$ D. W. Berreman, Phys. Rev. Lett. 28, 1683 (1972); Mol. Cryst. Liq. Cryst. 23, 215 (1973).

${ }^{6}$ M. Behdani, S. H. Keshmiri, S. Soria, M. A. Bader, J. Ihlemann, G. Marowsky, and Th. Rasing, Appl. Phys. Lett. 82, 2553 (2003).

${ }^{7}$ C. Marzolin, S. P. Smith, M. Prentiss, and G. M. Whitesides, Adv. Mater. (Weinheim, Ger.) 10, 571 (1998).

${ }^{8}$ Y. Xia and G. M. Whitesides, Angew. Chem., Int. Ed. 37, 551 (1998).

${ }^{9}$ C.-Y. Ting, D.-F. Ouyan, and B.-Z. Wan, J. Electrochem. Soc. 150, F164 (2003).

${ }^{10}$ M. Li, H. Tan, L. Chen, J. Wang, and S. Y. Chou, J. Vac. Sci. Technol. B 21, 660 (2003).

${ }^{11}$ G. P. Bryan-Brown, and I. C. Sage, Liq. Cryst. 20, 825 (1996).

${ }^{12}$ G. Baur, V. Wittwer, and D. W. Berreman, Phys. Lett. 56A, 142 (1976).

${ }^{13}$ D. H. Chung, T. Fukuda, Y. Takanishi, K. Ishikawa, H. Matsuda, H. Takezoe, and M. A. Osipov, J. Appl. Phys. 92, 1841 (2002). 